\title{
Poplar-Root Knot Nematode Interaction: A Model for Perennial Woody Species
}

\author{
Fabien Baldacci-Cresp, ${ }^{1}$ Pierre-Yves Sacré, ${ }^{2}$ Laure Twyffels, ${ }^{3}$ Adeline Mol, ${ }^{1}$ Marjorie Vermeersch, ${ }^{3}$ \\ Eric Ziemons, ${ }^{2}$ Philippe Hubert, ${ }^{2}$ David Pérez-Morga, ${ }^{3,4}$ Mondher El Jaziri, ${ }^{1}$ Janice de Almeida Engler, ${ }^{5}$ \\ and Marie Baucher ${ }^{1}$ \\ 1'Laboratoire de Biotechnologie Végétale, Université libre de Bruxelles, Rue des Professeurs Jeener et Brachet 12, B-6041 \\ Gosselies, Belgium; ${ }^{2}$ University of Liege, CIRM, Department of Pharmacy, Laboratory of Analytical Chemistry, CHU, B36, \\ B-4000 Liege, Belgium; ${ }^{3}$ Center for Microscopy and Molecular Imaging-CMMI, Université libre de Bruxelles; ${ }^{4}$ Laboratoire \\ de Parasitologie Moléculaire, Université libre de Bruxelles; and ${ }^{5}$ INRA, Université Nice Sophia Antipolis, CNRS, UMR 1355-7254 \\ Institut Sophia Agrobiotech, F-06900 Sophia Antipolis, France
}

Accepted 27 April 2016.

Plant root-knot nematode (RKN) interaction studies are performed on several host plant models. Though RKN interact with trees, no perennial woody model has been explored so far. Here, we show that poplar (Populus tremula $\times$ P. alba) grown in vitro is susceptible to Meloidogyne incognita, allowing this nematode to penetrate, to induce feeding sites, and to successfully complete its life cycle. Quantitative reverse transcriptionpolymerase chain reaction analysis was performed to study changes in poplar gene expression in galls compared with noninfected roots. Three genes (expansin A, histone 3.1, and asparagine synthase), selected as gall development marker genes, followed, during poplar-nematode interaction, a similar expression pattern to what was described for other plant hosts. Downregulation of four genes implicated in the monolignol biosynthesis pathway was evidenced in galls, suggesting a shift in the phenolic profile within galls developed on poplar roots. Raman microspectroscopy demonstrated that cell walls of giant cells were not lignified but mainly composed of pectin and cellulose. The data presented here suggest that RKN exercise conserved strategies to reproduce and to invade perennial plant species and that poplar is a suitable model host to study specific traits of tree-nematode interactions.

Root-knot nematodes (RKN) (Meloidogyne spp.) are sedentary obligate biotrophic plant parasites with a broad host range including more than 6,500 host plants. They are responsible for major economic damages caused to both annual and perennial plant species worldwide (Koenning et al. 1999; Trudgill and Blok 2001).

The life cycle of Meloidogyne incognita lasts from 4 to 8 weeks, depending on the host and the environmental conditions, and consists of four molts (Moens and Perry 2009). The first molt, from juvenile $\mathrm{J} 1$ to infective juvenile $\mathrm{J} 2$ stage, occurs within the egg. During the plant-RKN interaction, newly hatched J2s move to

J. de Almeida Engler and M. Baucher share senior authorship.

Corresponding author: M. Baucher; E-mail: mbaucher@ulb.ac.be

*The $\boldsymbol{e}$-Xtra logo stands for "electronic extra" and indicates that two supplementary figures and two supplementary tables are published online.

(c) 2016 The American Phytopathological Society the root elongation zone, migrating intercellularly toward the root apical meristem and turning upwards to the vascular cylinder (Caillaud et al. 2008). Then, J2s pierce five to seven vascular parenchymatic cells with their stylet and inject secretions containing effectors that contribute to the transdifferentiation of parenchymatic host cells into giant feeding cells (GCs) (Bellafiore and Briggs 2010; Bellafiore et al. 2008; Gheysen and Mitchum 2011; Jaubert et al. 2002). Subsequently, J2s become sedentary, feed from GCs, and then, molt into J3 and $\mathrm{J} 4$ stages to finally reach the female adult stage. $M$. incognita reproduces via parthenogenesis and males are only formed in adverse conditions (McClure and Viglierchio 1966; Triantaphyllou 1960). Males are vermiform and leave the root, whereas females are pear-shaped and lay eggs in a protective gelatinous matrix called an egg mass onto the host root surface or within the host root (Fernandez et al. 2015).

GC differentiation involves multiple mitotic events without cytokinesis, followed by several endoreduplication cycles causing nuclear and cellular enlargement (de Almeida Engler et al. 1999, 2004; Vieira et al. 2013). GCs are also characterized by cytoskeleton rearrangements, a fragmented vacuolar system, and an increased cytoplasm density with a large number of organelles, such as mitochondria, plastids, endoplasmic reticulum, Golgi stacks, and ribosomes (Banora et al. 2011; de Almeida Engler et al. 2004; Rodiuc et al. 2014). Typical patchy thickenings and ingrowths are seen in GC walls, as encountered in transfer cell walls (Cabrera et al. 2014; Rodiuc et al. 2014).

Plant-RKN interaction studies at the cellular and the molecular levels have been performed on several host plant models, such as Solanum lycopersicum, Arabidopsis thaliana, Lotus japonicus, Glycine max, and Medicago truncatula for dicots (Bartlem et al. 2014; Escobar et al. 2015; Holbein et al. 2016; Mantelin et al. 2015; Wieczorek 2015) and Oryza sativa for monocots (Kyndt et al. 2014). Tree-RKN interactions have been scarcely studied. Previous reports have shown that some tree species, like Salix alba and S. babylonica (Santamour and Batzli 1990) as well as Catalpa bignonioides (Sasanelli and Pierangeli 1994), are susceptible to RKN. The most documented impact of nematodes on tree species is on olive trees, leading to a reduction of growth mainly in nurseries (Ali et al. 2014).

In view of the economic and ecological importance of forest trees, research related to tree-RKN interaction deserves investigation. Poplars (Populus spp.) are trees of major 
agro-economic interest with high biomass productivity, used for pulping, veneer, timber, and biofuel production (Aylott et al. 2008; Polle et al. 2013). Poplar has been developed as a model to study specific traits of woody perennial plants, such as wood formation and seasonal dormancy (Jansson and Douglas 2007). Poplar-microorganism interactions have been studied, for instance, with Melampsora larici-populina (Azaiez et al. 2009) and mycorrhiza, such as Laccaria bicolor (Felten et al. 2009).

Here, we show that poplar $(P$. tremula $\times P$. alba $)$ can be considered as a model tree for interaction studies with the RKN M. incognita. Morphological and histological analyses of in vitro infection of poplar by $M$. incognita and its life cycle are described. We have shown that, at the molecular level, RKN gall development was accompanied by changes in gene expression, including expansin A (EXPA), histone 3.1 (H3.1), and asparagine synthase (ASNS), as well as genes associated to the monolignol biosynthesis pathway.

\section{RESULTS}

RKN galls are induced on poplar roots and allow nematodes to complete their life cycle.

To assess poplar susceptibility to $M$. incognita infection, around $100 \mathrm{~J} 2$ larvae were applied per 3-week-old in vitro plant. Typical root swellings caused by gall formation were observed in infected poplar roots at 7,14, and 21 days after inoculation (dai) (Fig. 1A to $\mathrm{C}$, respectively) but not in the corresponding 21-day-old uninfected roots (Fig. 1D). During gall expansion, a reddish coloration accumulated at its surface (Fig. 1A to C), probably due to the accumulation of anthocyanins in cortical gall cells (Hipskind et al. 1996). This coloration was not
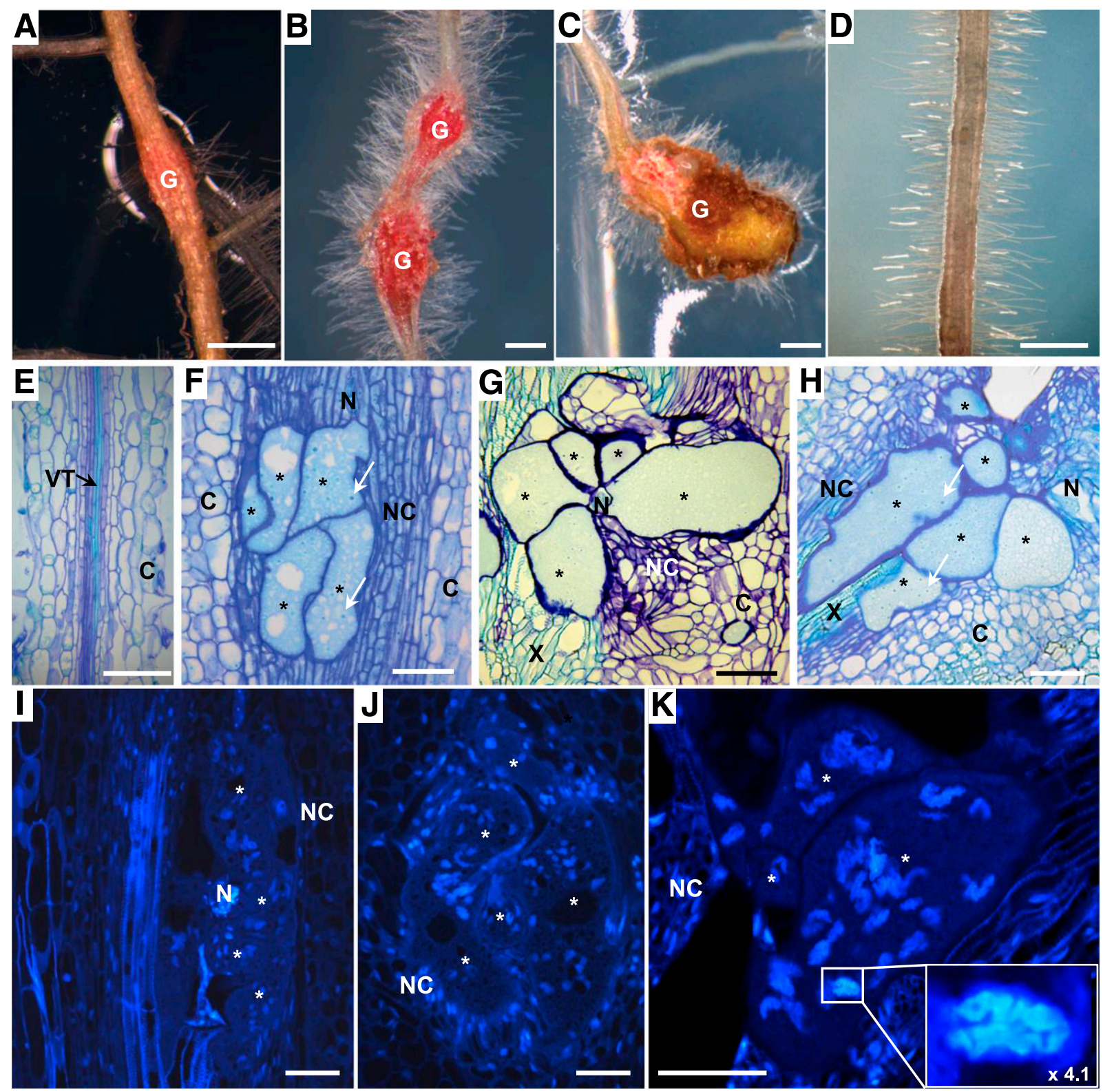

Fig. 1. Histological features of root-knot nematode gall development on in vitro poplar. A to $\mathbf{C}$, Galls at 7, 14, and 21 days after inoculation (dai). D, Uninfected root corresponding to infected root at 21 dai. $\mathbf{E}$ to $\mathbf{H}$, Longitudinal sections of an uninfected root and of 7-, 14-, and 21-dai galls, respectively, stained with toluidine blue. The white arrows indicate nuclei. I to K, Longitudinal sections of 7-, 14-, and 21-dai galls, respectively, stained with 4,6-diamidino2-phenylindole, showing enlarged nuclei in giant feeding cells $(\mathrm{GC}) . \mathrm{C}=$ cortex, $\mathrm{G}=$ gall, $\mathrm{N}=$ nematode, $\mathrm{NC}=$ neighboring cells, $\mathrm{VT}=$ vascular tissue, $\mathrm{X}=$ xylem. Asterisks $(*)$ indicate GC. Bars $=1 \mathrm{~mm}$ (A to D), 150 (E to H) and $100 \mu \mathrm{m}$ (I to K). 
observed on uninfected or in gall-free infected root segments. Longitudinal sections of uninfected poplar roots (Fig. 1E) and galls, made at the three different developmental stages, were stained with toluidine blue and were observed by light microscopy
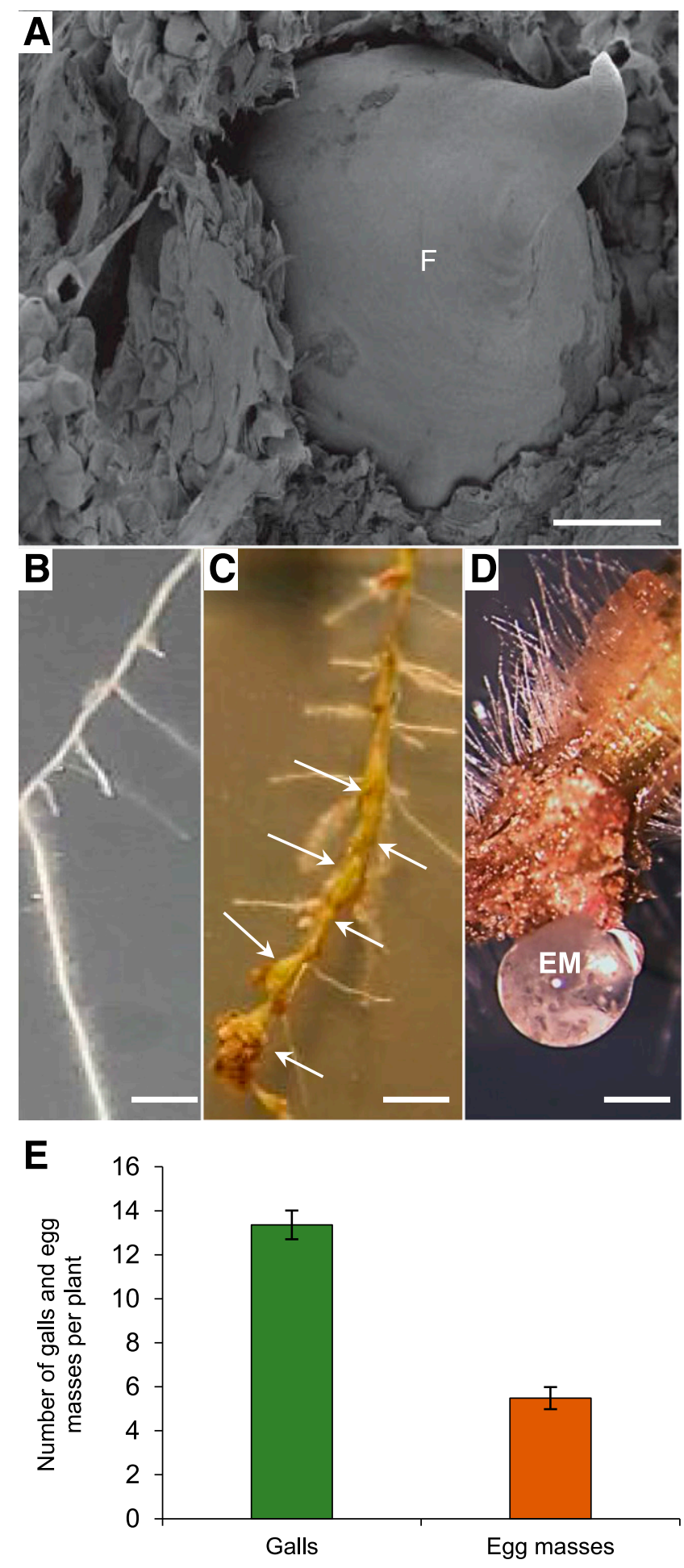

Fig. 2. Meloidogyne incognita female, gall, and egg mass observation and infection tests on in vitro poplar. A, Female of $M$. incognita, at 35 days after inoculation (dai) in a partially dissected gall, showing a typical pear-shaped morphology, as observed by scanning electron microscope. $\mathrm{F}=$ female. $\mathbf{B}$, Uninfected and $\mathbf{C}$, infected root at 21 dai (arrows show individual galls). D, Egg mass linked to a gall at 42 dai. E, Number of galls and egg masses per plant at 21 and 42 dai, respectively. Values are expressed as mean values \pm standard error for three independent experiments, $n \geq 15$ plants per experiment. $\mathrm{EM}=$ egg mass. Bars $=100 \mu \mathrm{m}(\mathrm{A}), 1 \mathrm{~cm}$ (B and C), and $1 \mathrm{~mm}(\mathrm{D})$.
(Fig. 1F to H). Developing galls, at 7 dai (Fig. 1F), contained GCs harboring several distinct nuclei (Fig. 1I), multiple small vacuoles, a dense cytoplasm, and were surrounded by dividing neighboring cells (NCs) within the vascular system, as typically observed on other plant hosts. At 14 and 21 dai (Fig. 1G and H, respectively), galls further developed within the root vascular tissue. Within GCs, the nuclei were numerous, enlarged, and often, clustered, showing irregular contours (Fig. 1J and 1K).

Typical pear-shaped female nematodes were observed by scanning electron microscopy (SEM) in partly dissected mature galls at 35 dai (Fig. 2A). Control and infected roots with multiple galls at 21 dai are illustrated in Figure $2 \mathrm{~B}$ and $\mathrm{C}$, respectively. Galls were recorded on infected roots at 21 dai (Fig. 2C) and egg masses at 42 dai (Fig. 2D). A mean of approximately 13 galls and five egg masses were counted per plant, demonstrating RKN infection and reproduction on in vitro grown poplar (Fig. 2E). Numerous galls at different developmental stages were observed 14 weeks after inoculation, corresponding to about two successive life cycles (Fig. 3A), indicating that eggs were able to hatch and to reinfect the plants. At this stage, suckers appeared on infected roots above and under the gall area (Fig. 3A and B), which was not observed on uninfected plants at the same age (Fig. 3C).

\section{GCs in poplar galls show cell-wall structures typical of transfer cells.}

Light and transmission electron microscopy (TEM) were used to visualize GC walls (Fig. 4). Fragments of aborted cell walls indicative of incomplete cytokinesis were observed (Fig. 4A). All GCs contained a dense cytoplasm filled with organelles (Fig. 4B), and their walls formed patchy thickenings and branched ingrowths not oriented to NCs (Fig. 4C to E). TEM images revealed that the $\mathrm{GC}$ walls displayed different staining intensities, probably representing different layers within the wall (Fig. 4F).

\section{Drastic xylem proliferation in poplar galls.}

Confocal microscopy was used to detect cell-wall autofluorescence under UV excitation in gall sections at 21 dai. Cell walls containing lignin usually show prominent autofluorescence, as observed in xylem elements in plant tissues (Donaldson 2013). Proliferation of xylem around GCs was conspicuous in poplar galls (Fig. 5A), compared with uninfected root (Fig. 5C). A closeup of the feeding site zone (Fig. 5B) shows a low autofluorescence of GC walls compared with xylem cell wall, suggesting the absence of lignin in the thickened GC walls. Xylem proliferation was also obvious in galls stained with toluidine blue (Fig. 5E), as compared with uninfected root (Fig. 5D).

\section{Raman analysis reveals chemical composition of the GC wall.}

Chemical composition of the GC wall was characterized by confocal Raman microspectroscopy, using galls at 21 dai. As a preliminary experiment and to validate the methodology on this material, a focus was made on the identification of cellulose, pectin, and lignin, which are the three main cell-wall components that are well-characterized with Raman microspectroscopy (Agarwal et al. 2013; Gierlinger and Schwanninger 2007; Gierlinger et al. 2012; Petry et al. 2003). Two main spectra from 464 to $1,853 \mathrm{~cm}^{-1}$ were identified in an $80-\mu \mathrm{m}$ gall cross-section comprising the whole feeding site surrounded by xylem and NCs (Supplementary Fig. S1A and B). The first spectrum presented a main peak at $1,600 \mathrm{~cm}^{-1}$ corresponding to lignin, which is mainly present in xylem cells, as seen during confocal microscopy observations. A second spectrum showed several major peaks, including the peak of pectin at $854 \mathrm{~cm}^{-1}$ and the characteristic double peak $\left(1,098\right.$ and $\left.1,120 \mathrm{~cm}^{-1}\right)$ corresponding to cellulose (Agarwal et al. 2013; Gierlinger et al. 2012). In 
parallel, Raman analysis was performed on an uninfected root (Supplementary Fig. S2). Further emphasis on the Raman analysis of the GC wall (Fig. 6A) illustrated a similar localization pattern for pectin and cellulose (Fig. 6B and D). These compounds presented a heterogeneous distribution within the GC wall. Spectra for pectin and cellulose are shown in Figure 6C and $\mathrm{E}$, respectively. No spectrum corresponding to lignin could be identified in the GC wall, confirming the lack of autofluorescence observed by confocal microscopy (Fig. 5).

\section{RKN-associated marker genes are expressed during poplar gall formation.}

To conduct expression analysis associated with poplar-RKN interaction, preliminary experiments were performed in order to select reference genes that can be used for expression normalization. A set of housekeeping genes for poplar (Pettengill et al. 2012) or for RKN-plant interaction in A. thaliana and Medicago truncatula (Baldacci-Cresp et al. 2012; Clément et al. 2009) was evaluated. Table 1 shows the expression stability of the different genes tested, using BestKeeper and NormFinder programs in uninfected roots and in galls at 7, 14, and 21 dai. As regards expression stability and considering all analyzed samples, including roots and galls, at all time points, NormFinder ranked $P T 1, C D C 2$, and $U B P 22$ and BestKeeper ranked Cyc063, PT1, $C D C 2$, and $U B P 22$ as suitable marker genes (Table 1). In addition, Table 1 displays data related to expression stability with respect to comparison of galls versus roots at different stages of gall development. According to the obtained results using the two algorithms, $P T 1, C Y C 063$, and $C D C 2$ were selected as suitable genes for expression normalization.

Gall marker genes have been reported for several plant hosts but, as far as we know, not yet for poplar or any other known host tree. These genes include defense genes usually downregulated during early stage of gall formation, as well as genes linked to gall development, and genes involved in primary metabolism generally described as upregulated in both developing and mature galls as compared with uninfected roots. Based on previous transcriptomic analysis (Baldacci-Cresp et al. 2012; Barcala et al. 2010; Grunewald et al. 2008; Hamamouch et al. 2011; Ibrahim et al. 2011; Jammes et al. 2005; Portillo et al. 2013), we selected pathogenesis-related protein 1 (PRI), WRKY23, and phenylalanine ammonia-lyase 3 (PAL3) as defense genes, EXPA, H3.1, and cell cycle switch protein 52A (CCS52A) for gall development, and cytosolic malate dehydrogenase (cMDH), ASNS, and nitrate reductase 2 (NR2) for carbon and nitrogen metabolism. Supplementary Table S1 gives details on the selected marker genes, their probable function, the RKN-plant interaction model, and their expression profiles upon infection.
The expression of these genes was analyzed at different stages of gall development in whole galls and was compared with their expression in corresponding uninfected poplar root (Fig. 7). Considering the defense genes, $P R l$ was up-regulated by 6.7 fold in galls at 7 dai, PAL3 was down-regulated by 1.9 -fold in galls at 14 dai, whereas WRKY23 was not differentially expressed in galls at 7, 14, or 21 dai (Fig. 7A). The genes associated with gall development, including EXPA and H3.1, were up-regulated at 7 dai (by 23.9- and 8.1-fold, respectively) and at both 14 and 21 dai (by about 9- and 2.5-fold, respectively), whereas CCS52A expression was not affected (Fig. 7B). For the genes involved in primary metabolism, $N R 2$ expression was not changed, $c M D H$ was down-regulated by 1.8 -fold at 7 dai but not differentially expressed at 14 and 21 dai, and ASNS was down-regulated by 2.3 -fold at 7 dai and by 1.6 -fold at both 14 and 21 dai (Fig. 7C). As a result, the expression profile of three genes can be selected as a marker for poplar-RKN interaction: the upregulation of EXPA and H3.1 for gall development and the downregulation of ASNS for gall metabolism, similarly to A. thaliana, Glycine max, and Medicago truncatula.

Since xylem development is induced in galls of poplar roots (Fig. 5), the expression of eight genes involved in the monolignol biosynthetic pathway was investigated during gall development (Fig. 8). These genes, including hydroxycinnamoyl-CoA shikimate/quinate hydroxycinnamoyl transferase 1 (HCT1), 4-coumarate 3-hydroxylase 3 (C3H3), caffeoyl CoA 3-O-methyltransferase 1/2 (CCoAOMT1/2), cinnamoyl-CoA reductase 2 (CCR2), ferulate 5-hydroxylase 1 and 2 (F5H1 and $\mathrm{F5H2}$ ), caffeic acid 3-O-methyltransferase (COMT2), and cinnamyl alcohol dehydrogenase 1 (CAD1), have been reported to be expressed in xylem (Shi et al. 2010). Their expression was analyzed in galls at 7, 14, and 21 dai and was compared with uninfected roots. As shown in Figure 8, HCT1 was down-regulated by 1.8- and 1.4-fold in galls at 7 and 14 dai, respectively, COMT2 was down-regulated by 1.4 -fold in galls at 14 dai, and both $F 5 H 1$ and $F 5 H 2$ were downregulated by two- to fourfold, depending on the stage of gall development analyzed, suggesting changes in the profile of monolignol and related compounds in RKN-infected poplar roots as compared with noninfected ones. The expression of the four other genes ( $C 3 H 3, C C o A O M T 1 / 2, C C R 2$, and $C A D 1)$ was not significantly different in infected and uninfected roots.

\section{DISCUSSION}

Poplar: a tree model host for RKN interaction.

Herein, we present poplar as a host of potential interest to study tree-RKN interaction. We show the successful
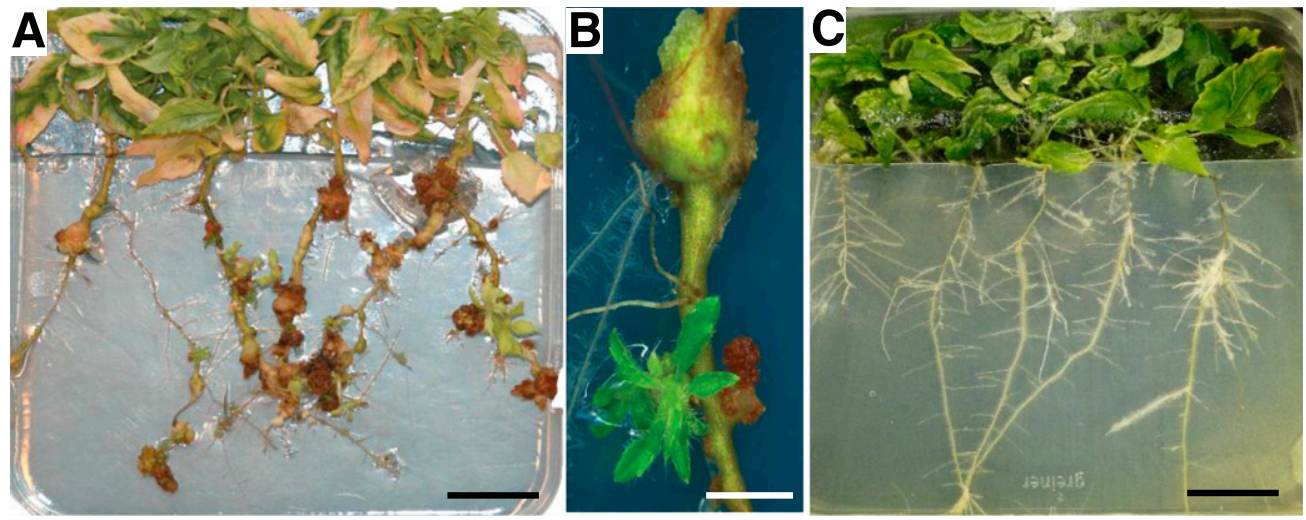

Fig. 3. De novo infection from a first inoculation and sucker production on in vitro poplar root. A, In vitro poplars 14 weeks after inoculation. B, Sucker produced close to a gall on the poplar root system. C, Uninfected in vitro poplars after 14 weeks. Bars $=2.1 \mathrm{~cm}(\mathrm{~A}$ and $\mathrm{C})$ and $2 \mathrm{~mm}(\mathrm{~B})$. The presence of suckers was observed on 15 plants spread on three biological replicates. 
completion of the life cycle of $M$. incognita on $P$. tremula $\times$ $P$. alba roots demonstrating the induction of functional feeding sites typically called 'galls.' Histological analysis revealed that feeding sites in poplar roots characteristically consisted of five to seven GCs with all distinctive features of RKN-induced galls. GCs presented a dense cytoplasm rich in organelles, multiple small vacuoles, cell-wall thickenings holding ingrowths, and an increased number of oversized nuclei with
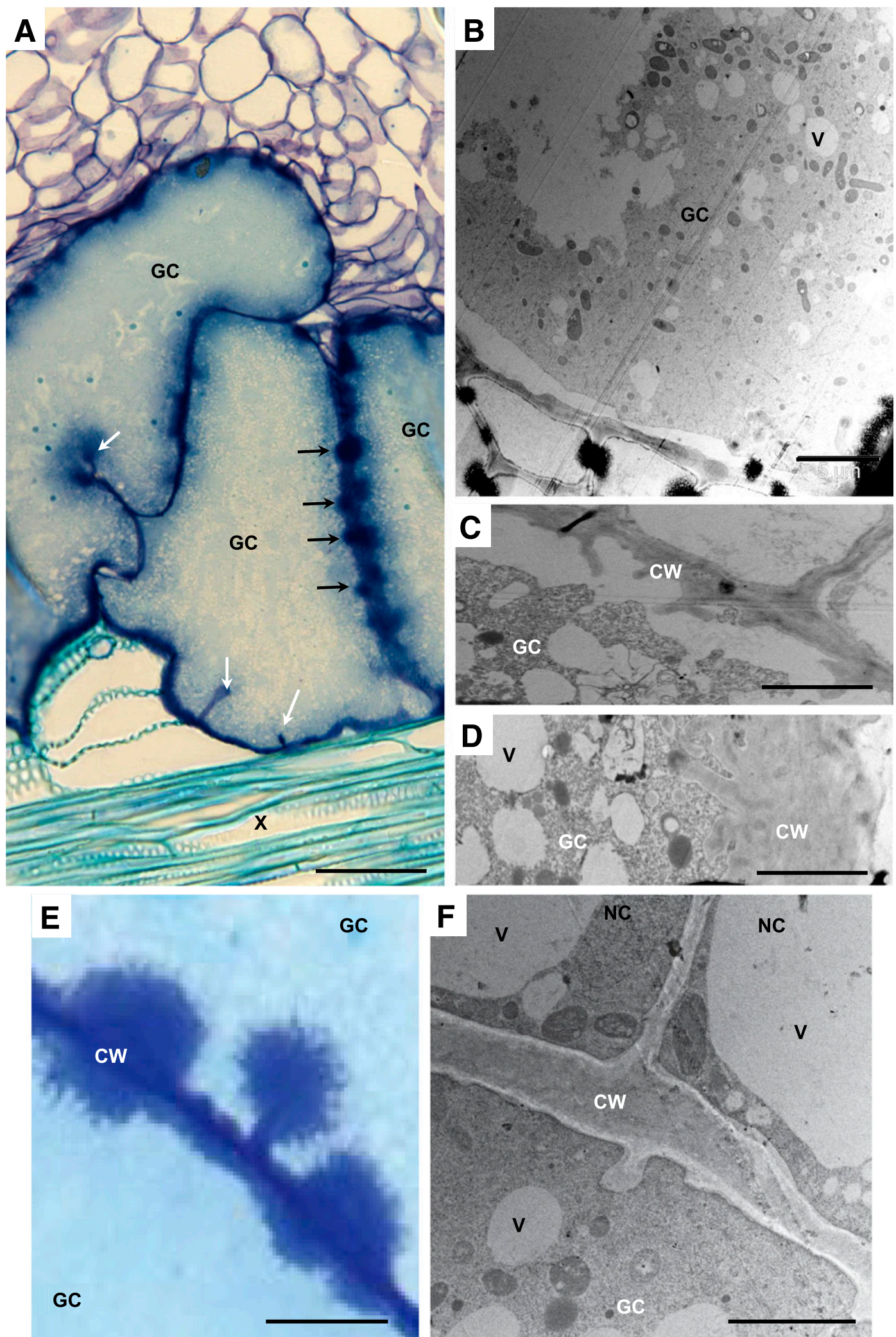

Fig. 4. Light and electron micrographs showing giant feeding cell (GC) wall thickenings at 21 days after inoculation. A, Section of a feeding site stained with toluidine blue. White arrows show aborted cell walls and black arrows show cell-wall thickening zones. B, An overview of a GC showing dense cytoplasm filled with organelles and $\mathbf{C}$ and $\mathbf{D}$, wall ingrowths. E, Cell-wall ingrowths between two GCs stained by toluidine blue. F, An electron micrograph of a GC with a thickened cell wall (CW) in contact with neighboring cells (NC) (with large vacuoles [V]). X = xylem. A, Bars = 50 (A), 5 (B), 1.4 (C), 2.3 (D), 17 (E), and $2 \mu \mathrm{m}(\mathrm{F})$. 
irregular shapes (Fig. 1). Characteristic cell-wall stubs resulting from an incomplete cytokinesis as well as cell-wall thickenings with profuse cell-wall ingrowths were also observed in GCs (Fig. 4). During feeding site development, nematodes matured into fertile females that laid viable egg masses capable of de novo infection (Fig. 3). Nematode life cycle was completed in about 6 weeks on in vitro-infected poplars.

The observed GC wall structures are similar to transfer cell walls and are considered to increase plasma membrane area, allowing enhanced nutrient exchange between cells (Rodiuc et al. 2014). As suggested by Baldacci-Cresp et al. (2015a), these cell-wall thickenings could also provide mechanical support to maintain cell shape in response to the high osmotic pressure present in galls. As far as we know, there is no report on the chemical composition of GC wall structures induced by RKN. Therefore, we performed Raman microspectroscopy to analyze cell-wall compounds in galls. Raman microspectroscopy is a nondestructive imaging technique, suitable for living organisms for the characterization of the molecular composition of a liquid or the outer part of a solid material (Brauchle and Schenke-Layland 2013; Gierlinger and Schwanninger 2007; Roman et al. 2011; Uragami et al. 2014). Based on this methodology, we were able to show that, in 21-dai galls, GC walls were composed of pectin and cellulose deposited heterogeneously. Besides, previous transcriptomic studies of whole galls or microdissected GCs indicate that the primary cell-wall metabolism is modified during plant-RKN interaction, as shown by the differential expression of genes coding for expansins, pectate lyases, pectin methylesterases, and glucanases (Damiani et al.
2012; Ibrahim et al. 2011; Jammes et al. 2005; Portillo et al. 2013). Raman analysis did not reveal lignin occurrence in GC walls. Similarly, by Wiesner staining, Ji et al. (2015) did not detect lignin in feeding sites in developing galls at 3, 5, and 7 dai in rice. In poplar galls, histological analysis (Fig. 5) revealed a strong natural autofluorescence indicative of drastic xylem development in galls around GCs. Xylem proliferation within RKN gall tissue was first described by Jones and Northcote (1972) in Coleus blumei, and this cytological feature was hypothesized to maintain vascular system continuity to compensate for anatomical disruption due to GC development and nematode presence inside the root structure (Goto et al. 2013). The overall observed features following poplar-RKN interaction are also encountered in other plant hosts, suggesting that RKN share conserved strategies to reproduce and to invade perennial plant species.

A peculiar observation was the induction of sucker formation at the poplar root-gall interface. Suckers were never observed in uninfected poplar roots during our in vitro experiments (Fig. $3)$. However, in vivo root suckering may occur under stress conditions as a vegetative reproduction mode of poplars from the Populus (Leuce Duby) section, of which P. tremula and $P$. alba are part (Slavov and Zhelev 2010). Wan et al. (2006) suggested that sucker development is possibly inhibited by the auxin produced in aerial parts and promoted by cytokinin, produced by the root apex, that accumulates in roots following disconnection from the stem. Indeed, Karczmarek et al. (2004) and Lohar et al. (2004) showed that hormonal balance is modified within gall tissue. One can hypothesize that the
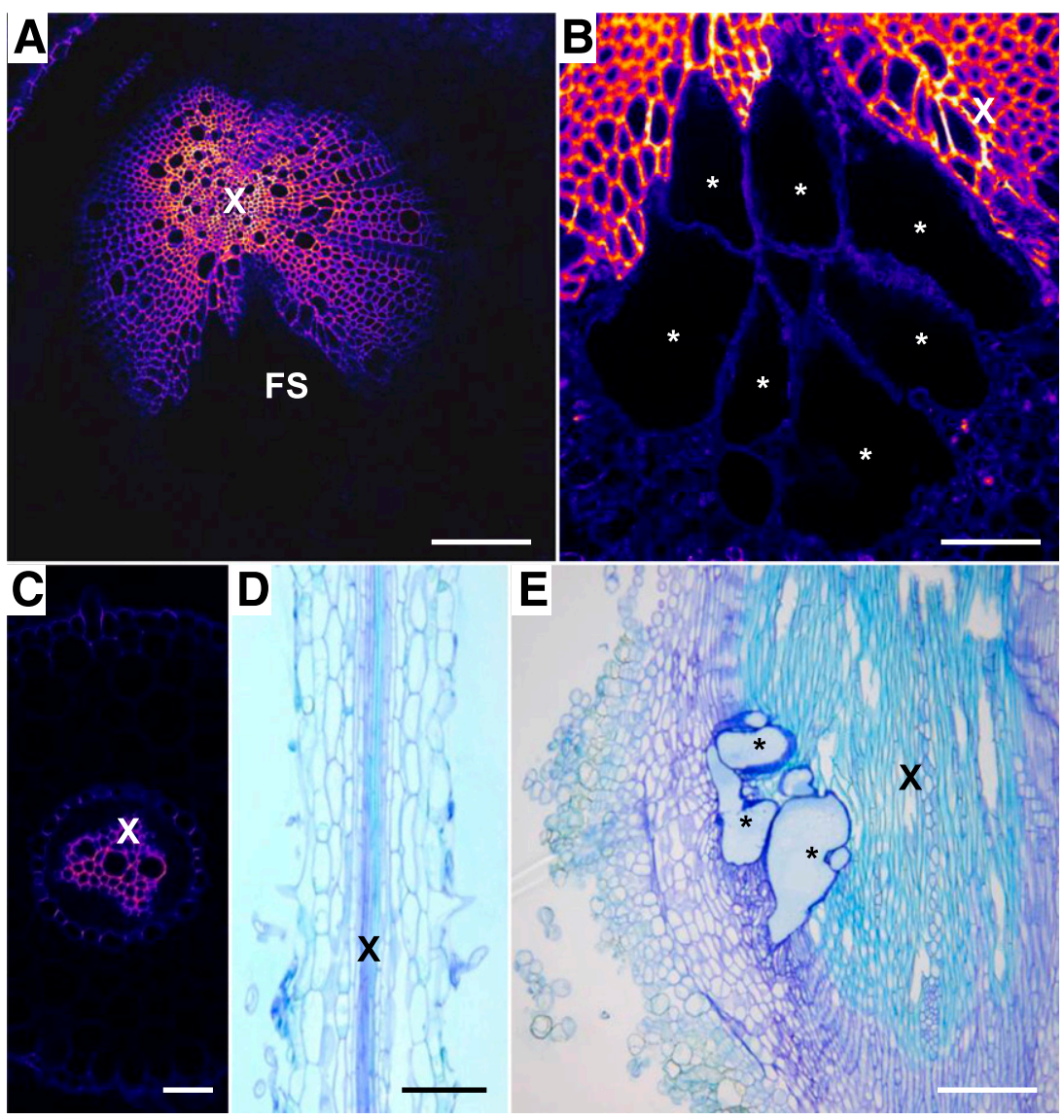

Fig. 5. Xylem development in galls 21 days after inoculation and corresponding uninfected root. A and $\mathbf{B}$, Autofluorescence of cell walls in a gall section and $\mathbf{C}$, in a cross section of an uninfected root. $\mathbf{D}$ and $\mathbf{E}$, Longitudinal sections of an uninfected root and of a gall, respectively, stained with toluidine blue. Images in A through $\mathrm{C}$ are represented in false color with an artificial 255 color intensity scale. $\mathrm{FS}=$ feeding site, $\mathrm{X}=\mathrm{xylem}$. Asterisks $(*)$ indicate $\mathrm{GC}$. Bars $=500(\mathrm{~A})$, 200 (B), 20 (C), 100 (D), and $250 \mu \mathrm{m}(\mathrm{E})$. 
A

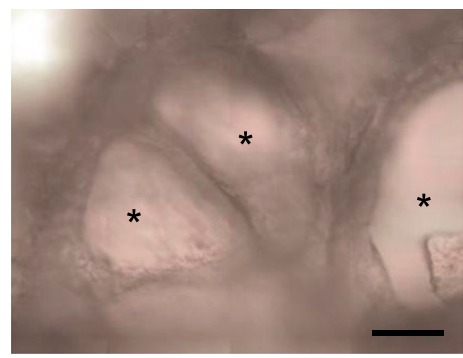

B

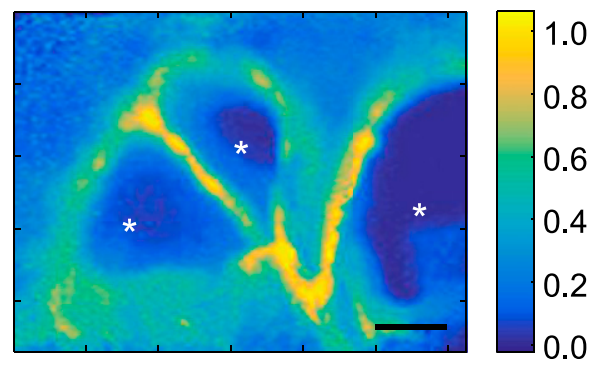

C

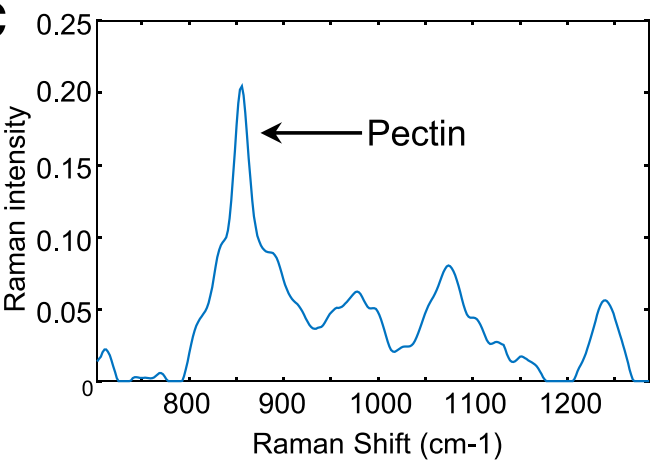

D
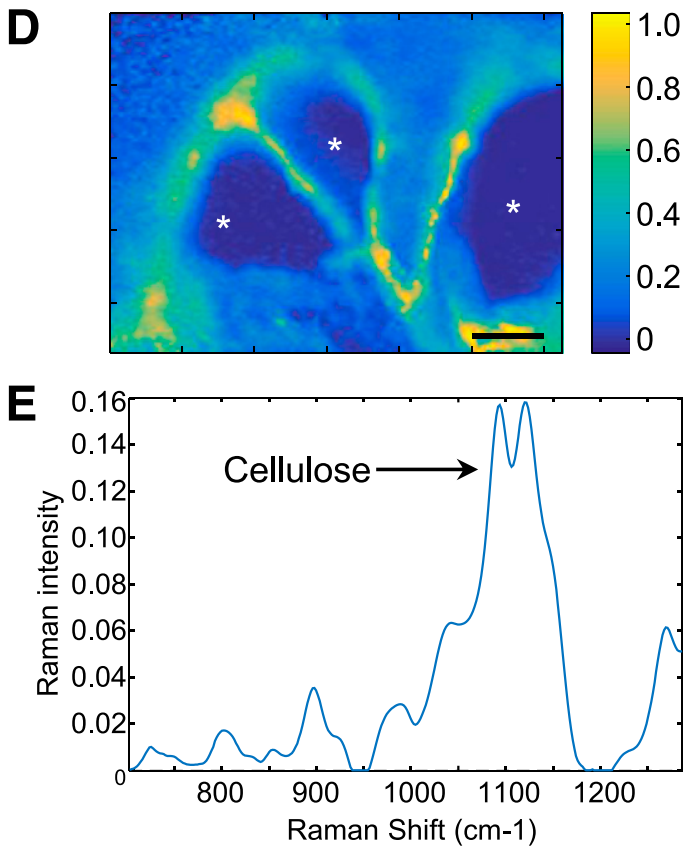

Fig. 6. Chemical characterization of giant feeding cell (GC) walls, with Raman microspectroscopy. A, A 80- $\mu$ m section in a feeding site 21 days after inoculation, observed by light microscopy. B, Pectin localization in the feeding site, with a dark (no pectin) to light (maximum pectin intensity) shade range. $\mathbf{C}$, Specific pectin-isolated spectra on the feeding site, analyzed between 700 and $1,300 \mathrm{~cm}^{-1}$. D, Cellulose localization in the feeding site with a dark (no cellulose) to light (maximum cellulose intensity) shade range. E, Specific cellulose-isolated spectra on the feeding site, analyzed between $700 \mathrm{~cm}$ and $1,300 \mathrm{~cm}^{-1}$. Asterisks (*) indicate GC. Bars $=50 \mu \mathrm{m}$ $(\mathrm{A}, \mathrm{B}$, and D). formation of suckers upon nematode infection is the result of changes in the hormonal balance within the root system following RKN infection. Profiling changes in auxin and cytokinin metabolism during poplar gall development may help to decipher the physiological processes associated to sucker development in elderly RKN-infected poplar roots cultured in vitro.

\section{Poplar RKN galls undergo conserved changes in gene expression.}

Three potential marker genes, showing similar altered expression levels in poplar galls as in other nematode hosts, were selected for analysis during poplar-RKN interaction (Fig. 7). The first gene, Potri.008G088300, encoding an expansin homologous to the Arabidopsis EXPA1, was up-regulated during poplar gall development stages at 7, 14, and 21 dai. EXPA1 was also up-regulated in A. thaliana galls at 7, 14, and 21 dai, together with six other EXPA genes and two EXPB genes (Jammes et al. 2005). Expansins are cell wall-loosening enzymes involved in the extension of the plant cell wall (Sampredo and Cosgrove 2005) and have been suggested to play a role in the establishment of RKN parasitism in tomato (Gal et al. 2006). A second gene, Potri.014G096900, encodes a histone H3.1 upregulated during all poplar gall development stages, similarly to its Arabidopsis homolog (Jammes et al. 2005). The histone H3.1 is part of the chromatin structure and the upregulation of its corresponding gene is most likely linked to transcription regulation occurring in galls (Ji et al. 2013). The third gene investigated, Potri.009G072900, coding for an ASNS (EC 6.3.5.4, an enzyme that generates asparagine from aspartate), was down-regulated during all analyzed gall developmental stages in poplar. Potri.009G072900 is homologous to Medicago truncatula ASNS2-1 (MTR_5g071360) also found

Table 1. Analysis of expression stability of reference genes for normalization using NormFinder and BestKeeper softwares

\begin{tabular}{|c|c|c|c|c|}
\hline \multicolumn{5}{|c|}{ NormFinder $^{\mathbf{a}}$} \\
\hline \multirow[b]{2}{*}{ Gene } & \multicolumn{4}{|c|}{ Stability value } \\
\hline & All samples & R7 vs. G7 & R14 vs. G14 & R21 vs. G21 \\
\hline CYCO63 & 0.02 & 0.018 & 0.027 & 0.018 \\
\hline PT1 & 0.006 & 0.015 & 0.001 & 0.002 \\
\hline$U B Q 7$ & 0.015 & 0.005 & 0.028 & 0 \\
\hline $18 S$ & 0.028 & 0.023 & 0.053 & 0.031 \\
\hline$C D C 2$ & 0.009 & 0.017 & 0.009 & 0 \\
\hline $40 S$ & 0.017 & 0.023 & 0.013 & 0.023 \\
\hline UBP22 & 0.013 & 0.007 & 0.002 & 0.018 \\
\hline \multicolumn{5}{|c|}{ BestKeeper $^{b}$} \\
\hline & \multicolumn{4}{|c|}{ Correlation coefficient } \\
\hline Gene & All samples & R7 vs. G7 & R14 vs. G14 & R21 vs. G21 \\
\hline CYC063 & 0.971 & 1.005 & 0.982 & 1.009 \\
\hline$P T 1$ & 0.835 & 1.001 & 1.019 & -0.898 \\
\hline$U B Q 7$ & 0.786 & -0.993 & 1.021 & 0.898 \\
\hline $18 S$ & -0.64 & 1.007 & -0.961 & 0.995 \\
\hline$C D C 2$ & 0.914 & 1.003 & -1.033 & 0.984 \\
\hline $40 S$ & -0.466 & -1 & -1.014 & -0.99 \\
\hline UBP22 & 0.835 & 1.003 & 1.006 & 0.993 \\
\hline
\end{tabular}

a The expression of each candidate reference gene was evaluated by the model-based and pairwise comparison approaches. A stability value close to 0 is indicative of high expression stability. The three best reference genes and values are shown in bold.

b Each candidate reference gene was compared with the BestKeeper Index to calculate a Pearson's coefficient of correlation. Correlation coefficients near to 1 indicate greater correlation with the index and, therefore, a high expression stability. The best reference genes and values are shown in bold. G7, G14, and G21, galls at 7, 14, and 21 dai, respectively. 
to be downregulated during Medicago-RKN interaction (BaldacciCresp et al. 2012).

The analysis of eight genes coding for enzymes involved in the monolignol biosynthesis pathway was investigated and revealed alteration in this biosynthesis pathway during RKN infection (Fig. 8). The biosynthesis pathway of the three main monolignols ( $p$-coumaroyl, coniferyl, and sinapyl alcohols) and their precursors comprises numerous enzymatic steps. This pathway starts with the general phenylpropanoid pathway, responsible for the production of $p$-coumaric acid from phenylalanine, which is common to a variety of molecules including hydroxycinnamic acids, flavonoids, stilbenes, coumarins, and monolignols (Vanholme et al. 2012a). Following their biosynthesis, the monolignols can be polymerized and incorporated into the lignin polymer and are then called the p-hydroxyphenyl (H), guaiacyl (G), and syringyl (S) units (Fig. 8A) (Boerjan et al. 2003). Alternatively, the monolignol biosynthesis pathway has been involved in the defense response of plants. Actually, enzymes of this pathway are induced upon defense (Naoumkina et al. 2010) and intermediates of the monolignol biosynthesis pathway have been reported to have nematicidal properties (Ohri and Pannu 2010). In this report, we show that $H C T 1, C O M T 2, F 5 H 1$, and $F 5 H 2$ are downregulated in whole gall tissues in poplar. Similarly, a global downregulation of the phenylpropanoid pathway was reported in rice galls (Kyndt et al. 2012). In poplar and with respect to lignin composition, a natural mutation of HCT has been shown to lead to an increase in the amount of $\mathrm{H}$ units (Vanholme et al. 2013) and the downregulation of COMT, decreasing the $\mathrm{S}$ unit content (Van Doorsselaere et al. 1995). F5H has been demonstrated to be a limiting enzyme for the synthesis of S units, as the F5H-deficient fah1 Arabidopsis mutant is devoid of S units (Meyer et al. 1998), whereas the C4H:F5H transgenic Arabidopsis (Meyer et al. 1998) or poplar (Franke et al. 2000) overexpressing $F 5 H$ have a lignin with an increased proportion of $\mathrm{S}$ units. Therefore, the downregulation of these four genes might suggest a modified lignin composition in poplar gall tissue.

However, it has been demonstrated that alteration of individual genes of the monolignol pathway may not only impact the lignin content and composition but have a wider impact at the metabolic level, resulting in a shift in the phenolic profile (Vanholme et al. 2012b). For instance, the comt and f5hl Arabidopsis mutant showed a downregulation in a gene involved in both shikimate and phenylpropanoid pathways albeit having normal lignin content (Vanholme et al. 2012b), suggesting changes in phenol-related secondary metabolites that might affect physiological and developmental processes. In that context, Wuyts et al. (2006) observed a lower fecundity (fewer eggs, juveniles, and mature females) for overexpressing $\mathrm{C} 4 \mathrm{H}$ : F5H Arabidopsis transgenic plants compared with the wild type. Besides, the transcriptomic analysis of transgenic tomato
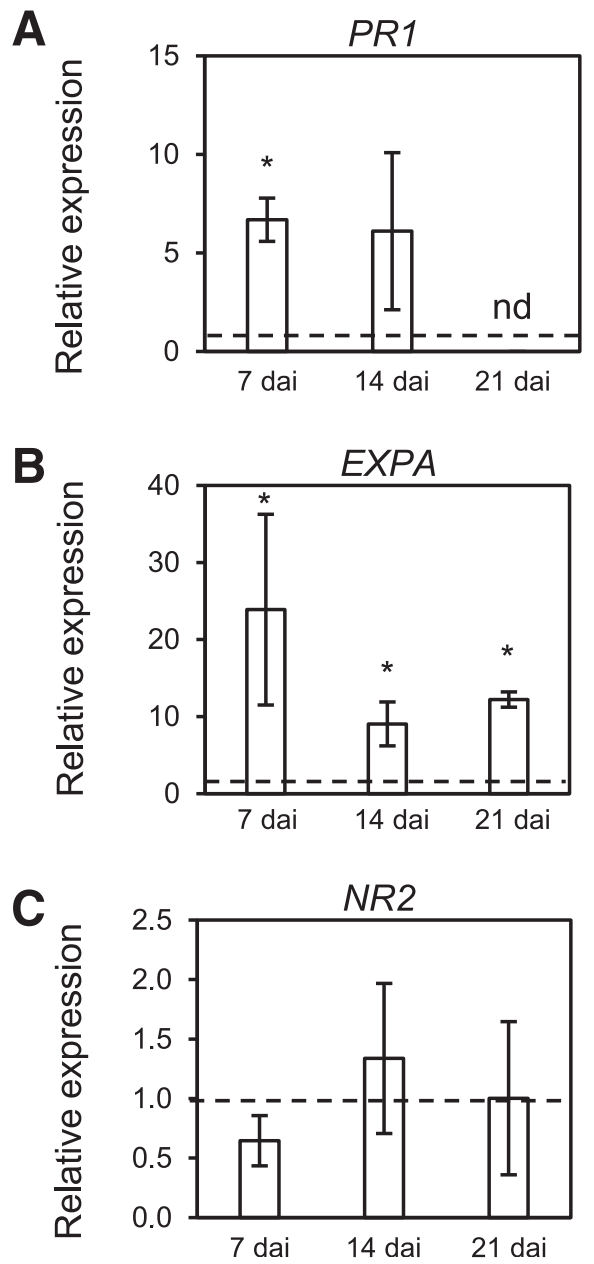
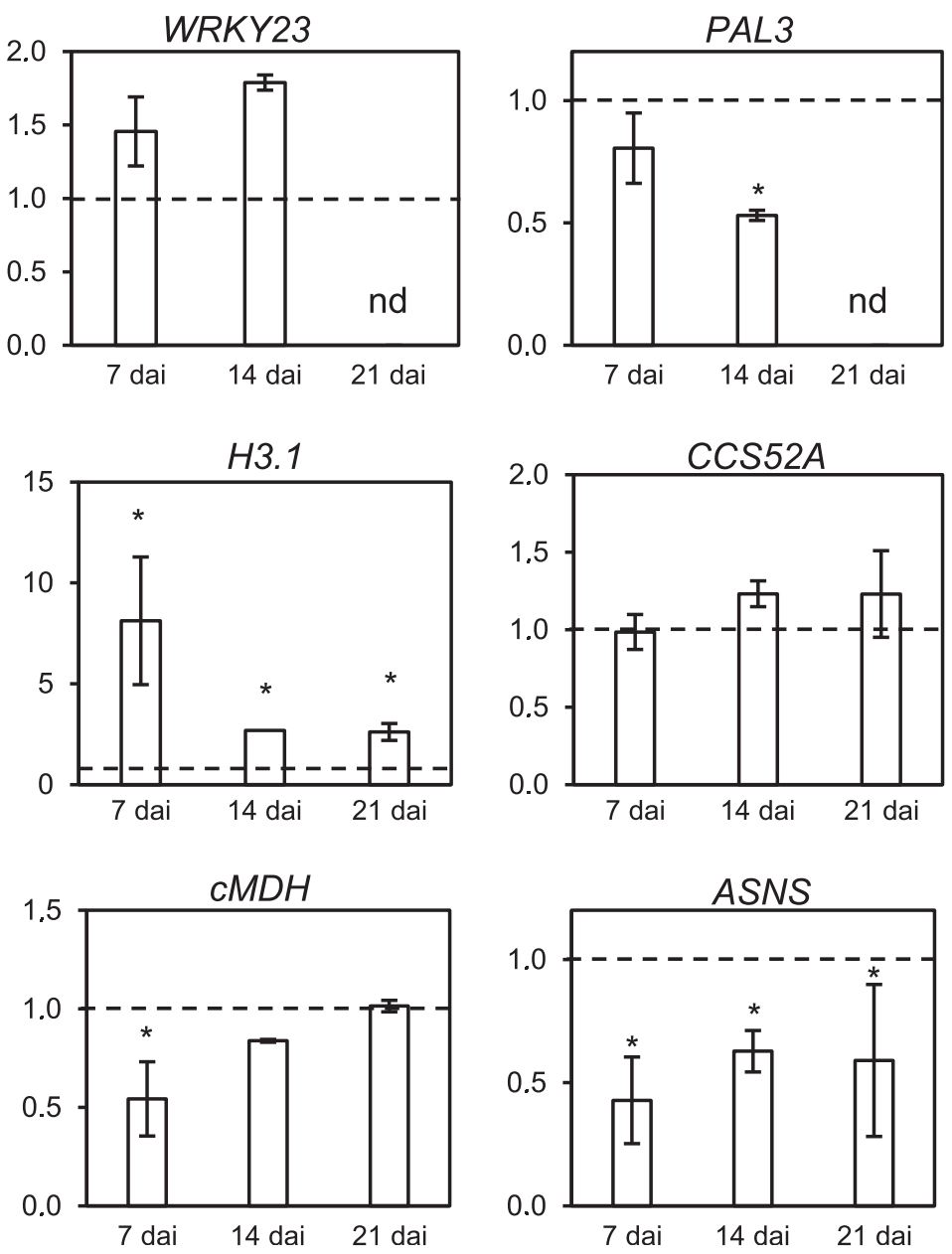

Fig. 7. Identification of marker genes for poplar root-knot nematode gall development. A, The relative expression of genes involved in plant defense (PRI, WRKY23, and PAL3), B, gall development (EXPA, H3.1, and CCS52A), and $\mathbf{C}$, gall metabolism (NR2, $C M D H$, and ASNS) was analyzed by quantitative reverse transcriptionpolymerase chain reaction in galls at 7, 14, and 21 days after inoculation (dai) and was compared with their expression in corresponding uninfected roots. Expression in uninfected root was normalized to 1 for each development stage and is represented by a dashed line. Values are expressed as mean values \pm standard error for three independent experiments. $n \geq 15$ plants per experiment. Statistical analysis was performed using Student's $t$ test. nd $=$ not determined. * indicates $P \leq 0.05$. 


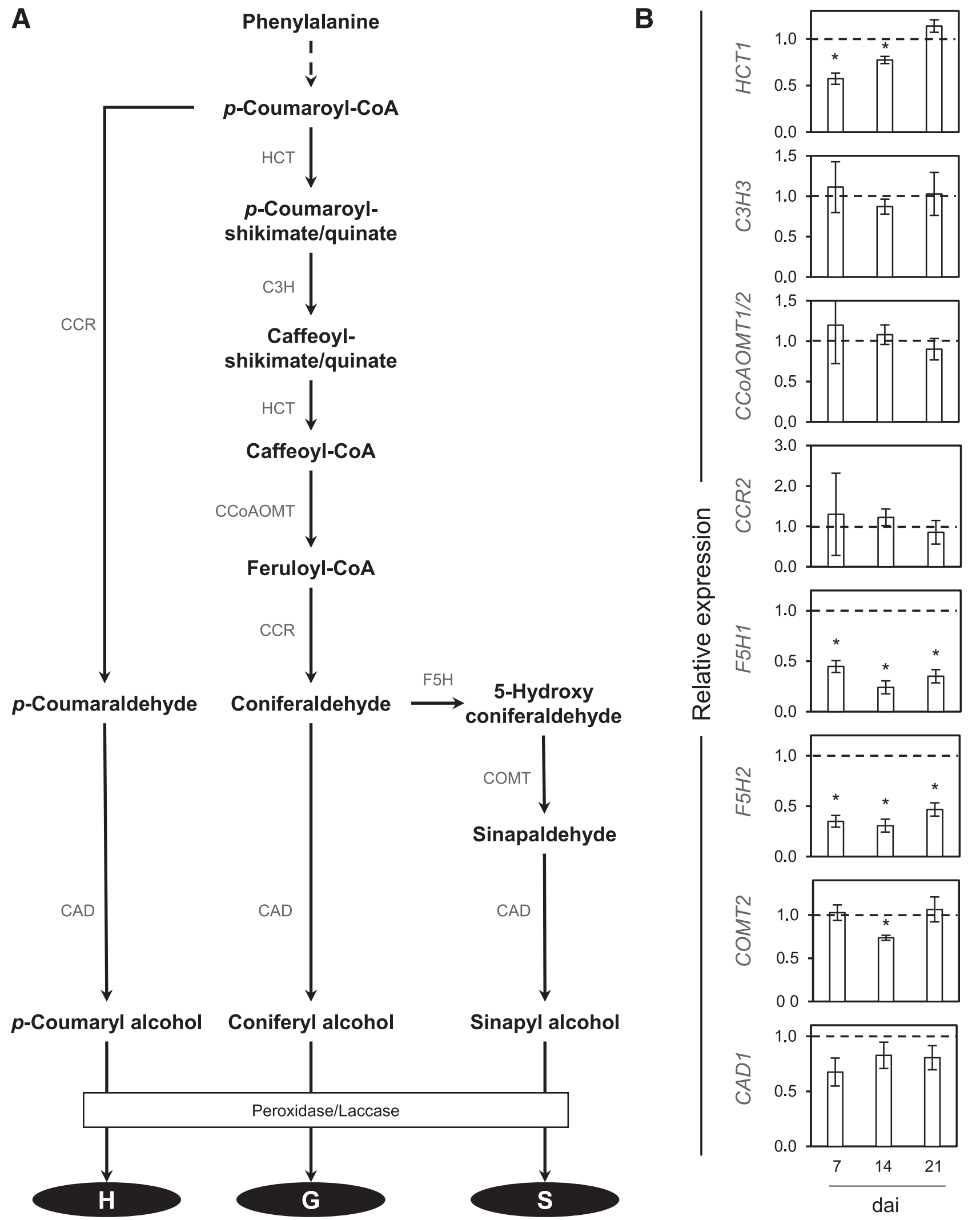

Fig. 8. Relative expression of genes coding for enzymes involved in the lignin biosynthesis pathway during root-knot nematode gall development in poplar root. A, Schematic view of the lignin biosynthesis pathway. B, Relative expression evaluated by quantitative reverse transcription-polymerase chain reaction in galls compared with corresponding uninfected roots at 7,14 , and 21 days after inoculation (dai). Values are expressed as mean values \pm standard error for three independent experiments. $n \geq 15$ plants per condition per experiment. Statistical analysis was performed using Student's $t$ test. * indicates $P \leq 0.05$. 
hairy roots overexpressing the $M$. javanica gene, encoding fatty acid-and retinol-binding protein (Mj-FAR-1), involved in nematode development and reproduction, has been shown to lead to downregulation of genes implicated in the phenylpropanoid pathway, such as PAL2 and $4 C L 3$ in noninfected roots (Iberkleid et al. 2015). As suggested by these authors, the nematode may repress the defense mechanisms of the plant to facilitate infection. Altogether, there is seemingly a link between RKN infection and the phenylpropanoid biosynthesis pathway. Further investigations on the occurrence and the role of phenylpropanoid-derived secondary metabolites during RKN interaction is required to better characterize RKN gall development in poplar. However, the expression analysis was made in whole poplar gall tissue including GCs, neighboring cells, and vascular tissues, therefore reflecting the global change during RKN-poplar interaction. The specific expression profile of particular cell types may be studied on microdissected tissues. In agreement with our general observation, a downregulation of the phenylpropanoid pathway was reported on microdissected GCs in both tomato and Arabidopsis (Portillo et al. 2013).

In conclusion, we demonstrate that poplar is a suitable host for RKN and we propose that the poplar-M. incognita interaction represents an attractive model to study this interface in woody perennial species. In addition, we have shown that several genes coding for enzymes of the phenylpropanoid biosynthesis pathway have an altered expression during RKN gall development, suggesting modifications in phenylpropanoid metabolism in poplar gall. As the proportion of lignified tissue, especially the xylem, is largely increased in polar galls and lignin is absent in GC walls, it is worthwhile to further investigate the impact of the modification of the phenylpropanoid pathway on poplar-RKN interaction by using specific poplar mutants in this pathway.

\section{MATERIALS AND METHODS}

Plant material, growth conditions, and nematode infection.

P. tremula $\times$ P. alba clone INRA 717 1-B4 was used in all experiments. Micropropagated poplars were cultured 15 days in sterile boxes (Duchefa, Haarlem, The Netherlands) containing WPM medium (Duchefa) supplemented with $0.7 \%$ agar under a photoperiod of $16 \mathrm{~h}$ of light and $8 \mathrm{~h}$ of darkness at $24^{\circ} \mathrm{C}(1,800$ to 2,200 lux, five fluorescent tubes; Fluora T8 Osram agro, München, Germany). Plants were transferred to squared plates $(12 \times 12 \mathrm{~cm})$ on WPM medium containing $1 \%$ agar. Before transfer, the medium was removed from 3 to $4 \mathrm{~cm}$ at the top of each plate to prevent a contact between the leaves and the medium. Plates were positioned horizontally for 2 days and were then inclined (around 45 degrees) for the rest of the experiment. To keep the roots in dark conditions, the plates were covered by aluminum foil at the level of the roots.

For nematode infection, approximately 100 surface-sterilized (Baldacci-Cresp et al. 2012) freshly hatched M. incognita J2 larvae were inoculated to each plant. After infection, plates were placed horizontally for $24 \mathrm{~h}$ and were then inclined (around 45 degrees) for the rest of the experiment. Galls (from 61 plants, four independent biological replicates) were counted at 21 dai and egg masses (from 56 plants, four independent biological replicates) were counted at 42 dai. For egg mass counting, infected roots were stained with a solution of Eosin Y (0.5 g/liter, staining of egg mass matrix) (Sigma-Aldrich, St. Louis) for $30 \mathrm{~min}$, were rinsed with water, and were observed with an Olympus SZX9 stereomicroscope (Olympus, Tokyo).
For Raman hyperspectral imaging analyses, inoculated plants were cultivated in the same conditions as above, but the plates were totally covered by aluminum foil, except for a small window $(2 \times 12 \mathrm{~cm})$ at the level of the aerial part, to limit chlorophyll synthesis due to the high autofluorescence background in Raman microspectroscopy analyses.

\section{Morphological analysis.}

Galls were collected at 7, 14, and 21 dai. Samples were fixed with $2.5 \%$ glutaraldehyde in $50 \mathrm{mM}$ phosphate buffered saline

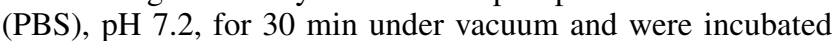
under rotation at $4^{\circ} \mathrm{C}$ for a minimum of $48 \mathrm{~h}$ (galls up to 14 dai) to 7 days (galls older than 14 dai). Galls were then dehydrated in increasing ethanol series (15 to $100 \%$ ethanol for $30 \mathrm{~min}$ each, followed by three times for $30 \mathrm{~min}$ in $100 \%$ ethanol). Samples were embedded in Technovit resin following manufacturer instructions (Technovit, Heraeus Kulzer, Hanau, Germany). Sections of $5 \mu \mathrm{m}$ were stained with $0.05 \%$ toluidine blue in distilled water, and images were taken using an Olympus BX60 microscope coupled with a Color View II camera (Olympus), using standard bright field optics. For nuclei observations, 5- $\mu \mathrm{m}$ sections were stained for $15 \mathrm{~min}$ with $1 \mu \mathrm{g}$ of 4',6-diamidino2-phenylindole per milliliter, which binds specifically to DNA.

\section{Confocal microscopy analysis.}

Sections of 80 to $150 \mu \mathrm{m}$, formed using a vibroslicer HM $650 \mathrm{~V}$ (Microm, Francheville, France), were imaged with a LSM710 confocal laser-scanning microscope (Zeiss, Jena, Germany) equipped with a $20 \times$ objective, using the proprietary ZEN software. Images show the autofluorescence of the sample, under $405 \mathrm{~nm}$ excitation.

\section{SEM and TEM analysis.}

For SEM, samples were fixed with $4 \%$ paraformaldehyde and $2.5 \%$ glutaraldehyde in $50 \mathrm{mM}$ PBS buffer, $\mathrm{pH}$ 7.2. Galls were then sectioned $(150 \mu \mathrm{m})$ with a vibroslicer HM $650 \mathrm{~V}$. Observations were made on a FEI Quanta 200 FEG electron microscope (FEI, Hillsboro, OR, U.S.A.) and were processed with AnalySIS and Adobe Photoshop softwares.

For TEM, the complete applied procedure was previously described by Baucher et al. (2011).

\section{Gene expression analysis by quantitative reverse transcription-polymerase chain reaction (RT-qPCR).}

For gene expression analysis, three independent biological replicates were analyzed. Each replicate was a pool of galls harvested from a minimum of 15 infected plants or a pool of roots harvested from a minimum of 25 uninfected plants. Total RNA was extracted using the Plant RNA isolation mini kit (Agilent Technology, Santa Clara, CA, U.S.A.), according to the manufacturer protocol with the following modifications. The first centrifugation was performed at $16,000 \times g$ for $10 \mathrm{~min}$ before the prefiltration column step and the second centrifugation during the wash step was performed at $20,000 \times g$. One microgram of RNA from whole gall and uninfected roots was reverse-transcribed using the reverse transcription system kit (Promega, Fitchburg, WI, U.S.A.). qPCR reactions were performed using a Light Cycler 480 II (Roche, Basel, Switzerland) and a qPCR MasterMix Light Cycler SYBR green I (Roche). In each reaction, $5 \mu \mathrm{l}$ of 50 -fold diluted cDNA and $0.3 \mu \mathrm{M}$ primer (primer sequences are given in Supplementary Table S2) were used. PCR was performed at $95^{\circ} \mathrm{C}$ for $2 \mathrm{~min}$, followed by 40 to 45 cycles at $95^{\circ} \mathrm{C}$ for $10 \mathrm{~s}, 60^{\circ} \mathrm{C}$ for $45 \mathrm{~s}$. Results are the mean of three independent biological experiments with technical duplicates. The specificity of the amplification was confirmed by a single peak in the dissociation curve at the end of the PCR reaction. Data were quantified using a Light Cycler II (Roche) 
and were normalized with the $2^{-\Delta \Delta C t}$ method (Livak and Schmittgen 2001). The endogenous controls were validated by BestKeeper and NormFinder application (Andersen et al. 2004) as presented above. The absence of genomic DNA contamination in the RNA samples was assessed according to BaldacciCresp et al. (2015b).

\section{Database, sequence, and statistical analysis.}

DNA sequences were analyzed using BLAST against the databases of the National Center for Biotechnology Information (http://blast.ncbi.nlm.nih.gov/) and Phytozome 11 (http:// phytozome.jgi.doe.gov/pz/portal.html).

All data represent, at minimum, three independent biological repetitions. Statistical analysis was performed using Student's $t$ test $(P \leq 0.05)$.

\section{Raman hyperspectral imaging analyses.}

Confocal Raman hyperspectral images of the GC walls were performed with a Labram HR Evolution (Horiba Scientific, Villeneuve-d'Ascq, France) equipped with a two-dimensional EMCCD detector $(1,600 \times 200$ pixels sensor) (Andor Technology Ltd., Belfast, Ireland), a Leica 50× Fluotar LWD objective and a 785-nm laser (XTRA II, Toptica Photonics AG, Gräfelfing, Germany) with a power of $45 \mathrm{~mW}$ at the sample (five galls from three independent biological replicates). A neutral-density filter reducing the laser power of $75 \%$ was used to preserve the sample from burning. The spectral range of 464 to $1,853 \mathrm{~cm}^{-1}$ was used to perform the mappings. Seven accumulations of 2-s exposures were used. The spectra were collected with the LabSpec 6 (Horiba Scientific) software. The feeding site image was mapped with a step resolution of $3 \mu \mathrm{m}$ and an image size of $94 \times 130$ pixels $(282 \times 390 \mu \mathrm{m})$.

For data processing, once acquired, the hyperspectral images were unfolded and the spectra were smoothed (Savitzky-Golay filter with a window width of 5) (Savitzky and Golay 1964) and baseline-corrected using the asymmetric least squares (Eilers 2004) algorithm. Pure spectra of the general map were resolved using multivariate curve resolution-alternating least squares (MCR-ALS) (Felten et al. 2015) with a nonnegativity constraint. The obtained spectra were compared with those presented in the literature (Chylińska et al. 2014; Gierlinger et al. 2012; Mansfield et al. 2013). Once the spectra of lignin, cellulose, and pectin were resolved, they were used to perform classical least squares analysis on the full map. The feeding site map was analyzed by MCR-ALS with nonnegativity constraint. All computations were realized with Matlab R2014b (version 8.4; The Matworks, Natick, MA, U.S.A.) and the PLS Toolbox 7.9.5 (Eigenvector Research, Wenatchee, WA, U.S.A.).

\section{ACKNOWLEDGMENTS}

We thank N. Marteu and M. Magliano for nematode production and A. Michaux and A. Bouwens for their help in experiments. F. BaldacciCresp received a grant post-doc IN from the BRIC (Université libre de Bruxelles) and is a post-doctoral researcher of the Fonds de la Recherche Scientifique (FRS-FNRS) in the frame of the research project T.0004.14 M. Baucher is a senior research associate of the FRS-FNRS. The Center for Microscopy and Molecular Imaging is supported by the European Regional Development Fund and Wallonia.

\section{LITERATURE CITED}

Agarwal, U. P., Reiner, R. R., and Ralph, S. A. 2013. Estimation of cellulose crystallinity of lignocelluloses using near-IR FT-Raman spectroscopy and comparison of the Raman and Segal-WAXS methods. J. Agric. Food Chem. 61:103-113.

Ali, N., Chapuis, E., Tavoillot, J., and Mateille, T. 2014. Plant-parasitic nematodes associated with olive tree (Olea europaea $L$.) with a focus on the Mediterranean basin: A review. C. R. Biol. 337:423-442.
Andersen, C. L., Jensen, J. L., and Ørntoft, T. F. 2004. Normalization of real-time quantitative reverse transcription-PCR data: A model-based variance estimation approach to identify genes suited for normalization, applied to bladder and colon cancer data sets. Cancer Res. 64:5245-5250.

Aylott, M. J., Casella, E., Tubby, I., Street, N. R., Smith, P., and Taylor, G. 2008. Yield and spatial supply of bioenergy poplar and willow shortrotation coppice in the UK. New Phytol. 178:358-370.

Azaiez, A., Boyle, B., Levée, V., and Séguin, A. 2009. Transcriptome profiling in hybrid poplar following interactions with Melampsora rust fungi. Mol. Plant-Microbe Interact 22:190-200.

Baldacci-Cresp, F., Chang, C., Maucourt, M., Deborde, C., Hopkins, J., Lecomte, P., Bernillon, S., Brouquisse, R., Moing, A., Abad, P., Hérouart, D., Puppo, A., Favery, B., and Frendo, P. 2012. (Homo)glutathione deficiency impairs root-knot nematode development in Medicago truncatula. PLoS Pathog. 8:e1002471.

Baldacci-Cresp, F., Maucourt, M., Deborde, C., Pierre, O., Moing, A., Brouquisse, R., Favery, B., and Frendo, P. 2015a. Maturation of nematode-induced galls in Medicago truncatula is related to water status and primary metabolism modifications. Plant Sci. 232:77-85.

Baldacci-Cresp, F., Moussawi, J., Leplé, J. C., Van Acker, R., Kohler, A., Candiracci, J., Twyffels, L., Spokevicius, A. V., Bossinger, G., Laurans, F., Brunel, N., Vermeersch, M., Boerjan, W., El Jaziri, M., and Baucher, M. 2015b. PtaRHE1, a Populus tremula $\times$ Populus alba RING-H2 protein of the ATL family, has a regulatory role in secondary phloem fibre development. Plant J. 82:978-990.

Banora, M. Y., Rodiuc, N., Baldacci-Cresp, F., Smertenko, A., BleveZacheo, T., Mellilo, M. T., Karimi, M., Hilson, P., Evrard, J. L., Favery, B., Engler, G., Abad, P., and de Almeida Engler, J. 2011. Feeding cells induced by phytoparasitic nematodes require $\gamma$-tubulin ring complex for microtubule reorganization. PLoS Pathog. 7:e1002343.

Barcala, M., García, A., Cabrera, J., Casson, S., Lindsey, K., Favery, B., García-Casado, G., Solano, R., Fenoll, C., and Escobar, C. 2010. Early transcriptomic events in microdissected Arabidopsis nematode-induced giant cells. Plant J. 61:698-712.

Bartlem, D. G., Jones, M. G. K., and Hammes, U. Z. 2014. Vascularization and nutrient delivery at root-knot nematode feeding sites in host roots. J. Exp. Bot. 65:1789-1798.

Baucher, M., Oukouomi Lowe, Y., Vandeputte, O. M., Mukoko Bopopi, J., Moussawi, J., Vermeersch, M., Mol, A., El Jaziri, M., Homblé, F., and Pérez-Morga, D. 2011. Ntann12 annexin expression is induced by auxin in tobacco roots. J. Exp. Bot. 62:4055-4065.

Bellafiore, S., and Briggs, S. P. 2010. Nematode effectors and plant responses to infection. Curr. Opin. Plant Biol. 13:442-448.

Bellafiore, S., Shen, Z., Rosso, M. N., Abad, P., Shih, P., and Briggs, S. P. 2008. Direct identification of the Meloidogyne incognita secretome reveals proteins with host cell reprogramming potential. PLoS Pathog. 4:e1000192.

Boerjan, W., Ralph, J., and Baucher, M. 2003. Lignin biosynthesis. Annu. Rev. Plant Biol. 54:519-546.

Brauchle, E., and Schenke-Layland, K. 2013. Raman spectroscopy in biomedicine-Non-invasive in vitro analysis of cells and extracellular matrix components in tissues. Biotechnol. J. 8:288-297.

Cabrera, J., Barcala, M., Fenoll, C., and Escobar, C. 2014. Transcriptomic signatures of transfer cells in early developing nematode feeding cells of Arabidopsis focused on auxin and ethylene signaling. Front. Plant Sci. 5:107.

Caillaud, M. C., Dubreuil, G., Quentin, M., Perfus-Barbeoch, L., Lecomte, P., de Almeida Engler, J., Abad, P., Rosso, M. N., and Favery, B. 2008. Root-knot nematodes manipulate plant cell functions during a compatible interaction. J. Plant Physiol. 165:104-113.

Chylińska, M., Szymańska-Chargot, M., and Zdunek, A. 2014. Imaging of polysaccharides in the tomato cell wall with Raman microspectroscopy. Plant Methods 10:14.

Clément, M., Ketelaar, T., Rodiuc, N., Banora, M. Y., Smertenko, A., Engler, G., Abad, P., Hussey, P. J., and de Almeida Engler, J. 2009. Actin-depolymerizing factor2-mediated actin dynamics are essential for root-knot nematode infection of Arabidopsis. Plant Cell 21:2963-2979.

Damiani, I., Baldacci-Cresp, F., Hopkins, J., Andrio, E., Balzergue, S., Lecomte, P., Puppo, A., Abad, P., Favery, B., and Hérouart, D. 2012. Plant genes involved in harbouring symbiotic rhizobia or pathogenic nematodes. New Phytol. 194:511-522.

de Almeida Engler, J., De Vleesschauwer, V., Burssens, S., Celenza, J. L. Jr., Inzé, D., Van Montagu, M., Engler, G., and Gheysen, G. 1999. Molecular markers and cell cycle inhibitors show the importance of cell cycle progression in nematode-induced galls and syncytia. Plant Cell 11: 793-808.

de Almeida Engler, J., Van Poucke, K., Karimi, M., De Groodt, R., Gheysen, G., Engler, G., and Gheysen, G. 2004. Dynamic cytoskeleton 
rearrangements in giant cells and syncytia of nematode-infected roots. Plant J. 38:12-26.

Donaldson, L. 2013. Softwood and hardwood lignin fluorescence spectra of wood cell walls in different mouting media. IAWA J. 34:3-19.

Eilers, P. H. C. 2004. Parametric time warping. Anal. Chem. 76:404-411.

Escobar, C., Barcala, M., Cabrera, J., and Fenoll, C. 2015. Overview of root-knot nematodes and giant cells. Pages 1-32 in: Advances in Botanical Research, Vol 73. Elsevier Ltd., Amsterdam.

Felten, J., Hall, H., Jaumot, J., Tauler, R., de Juan, A., and Gorzsás, A. 2015. Vibrational spectroscopic image analysis of biological material using multivariate curve resolution-alternating least squares (MCR-ALS). Nat. Protoc. 10:217-240.

Felten, J., Kohler, A., Morin, E., Bhalerao, R. P., Palme, K., Martin, F., Ditengou, F. A., and Legué, V. 2009. The ectomycorrhizal fungus Laccaria bicolor stimulates lateral root formation in poplar and Arabidopsis through auxin transport and signaling. Plant Physiol. 151:1991-2005.

Fernandez, D., Petitot, A.-S., Grossi de Sá, M., Nguyễn, V. P., de Almeida Engler, J., and Kyndt, T. 2015. Recent advances in understanding plantnematode interactions in monocots. Pages 189-219 in: Advances in Botanical Research, Vol 73. Elsevier Ltd., Amsterdam.

Franke, R., McMichael, C. M., Meyer, K., Shirley, A. M., Cusumano, J. C., and Chapple, C. 2000. Modified lignin in tobacco and poplar plants overexpressing the Arabidopsis gene encoding ferulate 5-hydroxylase. Plant J. 22:223-234.

Gal, T. Z., Aussenberg, E. R., Burdman, S., Kapulnik, Y., and Koltai, H 2006. Expression of a plant expansin is involved in the establishment of root knot nematode parasitism in tomato. Planta 224:155-162.

Gheysen, G., and Mitchum, M. G. 2011. How nematodes manipulate plant development pathways for infection. Curr. Opin. Plant Biol. 14:415-421.

Gierlinger, N., Keplinger, T., and Harrington, M. 2012. Imaging of plant cell walls by confocal Raman microscopy. Nat. Protoc. 7:1694-1708.

Gierlinger, N., and Schwanninger, M. 2007. The potential of Raman microscopy and Raman imaging in plant research. Spectroscopy (Springf.) 21:69-89.

Goto, D. B., Miyazawa, H., Mar, J. C., and Sato, M. 2013. Not to be suppressed? Rethinking the host response at a root-parasite interface. Plant Sci. 213:9-17.

Grunewald, W., Karimi, M., Wieczorek, K., Van de Cappelle, E., Wischnitzki, E., Grundler, F., Inzé, D., Beeckman, T., and Gheysen, G. 2008. A role for AtWRKY23 in feeding site establishment of plantparasitic nematodes. Plant Physiol. 148:358-368.

Hamamouch, N., Li, C., Seo, P. J., Park, C. M., and Davis, E. L. 2011. Expression of Arabidopsis pathogenesis-related genes during nematode infection. Mol. Plant Pathol. 12:355-364.

Hipskind, J., Wood, K., and Nicholson, R. L. 1996. Localized stimulation of anthocyanin accumulation and delineation of pathogen ingress in maize genetically resistant to Bipolaris maydis race O. Physiol. Mol. Plant Pathol. 49:247-256.

Holbein, J., Grundler, F. M. W., and Siddique, S. 2016. Plant basa resistance to nematodes: An update. J. Exp. Bot. 67:2049-2061.

Iberkleid, I., Sela, N., and Brown Miyara, S. 2015. Meloidogyne javanica fatty acid- and retinol-binding protein (Mj-FAR-1) regulates expression of lipid-, cell wall-, stress- and phenylpropanoid-related genes during nematode infection of tomato. BMC Genomics 16:272.

Ibrahim, H. M., Hosseini, P., Alkharouf, N. W., Hussein, E. H., Gamal ElDin, Ael. K., Aly, M. A., and Matthews, B. F. 2011. Analysis of gene expression in soybean (Glycine max) roots in response to the root knot nematode Meloidogyne incognita using microarrays and KEGG pathways. BMC Genomics 12:220.

Jammes, F., Lecomte, P., de Almeida-Engler, J., Bitton, F., MartinMagniette, M. L., Renou, J. P., Abad, P., and Favery, B. 2005. Genomewide expression profiling of the host response to root-knot nematode infection in Arabidopsis. Plant J. 44:447-458.

Jansson, S., and Douglas, C. J. 2007. Populus: A model system for plant biology. Annu. Rev. Plant Biol. 58:435-458.

Jaubert, S., Ledger, T. N., Laffaire, J. B., Piotte, C., Abad, P., and Rosso, M. N. 2002. Direct identification of stylet secreted proteins from rootknot nematodes by a proteomic approach. Mol. Biochem. Parasitol. 121: 205-211.

Ji, H., Gheysen, G., Denil, S., Lindsey, K., Topping, J. F., Nahar, K., Haegeman, A., De Vos, W. H., Trooskens, G., Van Criekinge, W., De Meyer, T., and Kyndt, T. 2013. Transcriptional analysis through RNA sequencing of giant cells induced by Meloidogyne graminicola in rice roots. J. Exp. Bot. 64:3885-3898

Ji, H., Kyndt, T., He, W., Vanholme, B., and Gheysen, G. 2015. $\beta$-Aminobutyric acid-induced resistance against root-knot nematodes in rice is based on increased basal defense. Mol. Plant-Microbe Interact 28:519-533.
Jones, M. G. K., and Northcote, D. H. 1972. Multinucleate transfer cells induced in coleus roots by the root-knot nematode, Meloidogyne arenaria. Protoplasma 75:381-395.

Karczmarek, A., Overmars, H., Helder, J., and Goverse, A. 2004. Feeding cell development by cyst and root-knot nematodes involves a similar early, local and transient activation of a specific auxin-inducible promoter element. Mol. Plant Pathol. 5:343-346.

Koenning, S. R., Overstreet, C., Noling, J. W., Donald, P. A., Becker, J. O., and Fortnum, B. A. 1999. Survey of crop losses in response to phytoparasitic nematodes in the United States for 1994. J. Nematol. 31 (4S):587-618.

Kyndt, T., Denil, S., Haegeman, A., Trooskens, G., Bauters, L., Van Criekinge, W., De Meyer, T., and Gheysen, G. 2012. Transcriptional reprogramming by root knot and migratory nematode infection in rice. New Phytol. 196:887-900.

Kyndt, T., Fernandez, D., and Gheysen, G. 2014. Plant-parasitic nematode infections in rice: Molecular and cellular insights. Annu. Rev. Phytopathol. 52:135-153.

Livak, K. J., and Schmittgen, T. D. 2001. Analysis of relative gene expression data using real-time quantitative PCR and the $2^{-\Delta} \Delta \mathrm{C}(\mathrm{T})$ method. Methods 25:402-408.

Lohar, D. P., Schaff, J. E., Laskey, J. G., Kieber, J. J., Bilyeu, K. D., and Bird, D. M. 2004. Cytokinins play opposite roles in lateral roo formation, and nematode and rhizobial symbioses. Plant J. 38:203-214

Mansfield, J. C., Littlejohn, G. R., Seymour, M. P., Lind, R. J., Perfect, S., and Moger, J. 2013. Label-free chemically specific imaging in planta with stimulated Raman scattering microscopy. Anal. Chem. 85: 5055-5063.

Mantelin, S., Thorpe, P., and Jones, J. T. 2015. Suppression of plant defences by plant-parasitic nematodes. Pages 325-337 in: Advances in Botanical Research, Vol 73. Elsevier Ltd., Amsterdam.

McClure, M. A., and Viglierchio, D. R. 1966. The influence of host nutrition and intensity of infection on the sex ratio and development of Meloidogyne incognita in sterile agar cultures of excised cucumber roots. Nematologica 12:248-258.

Meyer, K., Shirley, A. M., Cusumano, J. C., Bell-Lelong, D. A., and Chapple, C. 1998. Lignin monomer composition is determined by the expression of a cytochrome P450-dependent monooxygenase in Arabidopsis. Proc. Natl. Acad. Sci. U.S.A. 95:6619-6623.

Moens, M., and Perry, R. N. 2009. Migratory plant endoparasitic nematodes: A group rich in contrasts and divergence. Annu. Rev. Phytopathol. 47:313-332.

Naoumkina, M. A., Zhao, Q., Gallego-Giraldo, L., Dai, X., Zhao, P. X., and Dixon, R. A. 2010. Genome-wide analysis of phenylpropanoid defence pathways. Mol. Plant Pathol. 11:829-846.

Ohri, P., and Pannu, S. K. 2010. Effect of phenolic compounds on nematodes-A review. J. App. Nat. Sci. 2:344-350.

Petry, R., Schmitt, M., and Popp, J. 2003. Raman spectroscopy-A prospective tool in the life sciences. ChemPhysChem 4:14-30.

Pettengill, E. A., Parmentier-Line, C., and Coleman, G. D. 2012. Evaluation of qPCR reference genes in two genotypes of Populus for use in photoperiod and low-temperature studies. BMC Res. Notes 5:366.

Polle, A., Janz, D., Teichmann, T., and Lipka, V. 2013. Poplar genetic engineering: Promoting desirable wood characteristics and pest resistance. Appl. Microbiol. Biotechnol. 97:5669-5679.

Portillo, M., Cabrera, J., Lindsey, K., Topping, J., Andrés, M. F., Emiliozzi, M., Oliveros, J. C., García-Casado, G., Solano, R., Koltai, H., Resnick, N., Fenoll, C., and Escobar, C. 2013. Distinct and conserved transcriptomic changes during nematode-induced giant cell development in tomato compared with Arabidopsis: A functional role for gene repression. New Phytol. 197:1276-1290.

Rodiuc, N., Vieira, P., Banora, M. Y., and de Almeida Engler, J. 2014. On the track of transfer cell formation by specialized plant-parasitic nematodes. Front. Plant Sci. 5:160.

Roman, M., Dobrowolski, J. C., Baranska, M., and Baranski, R. 2011. Spectroscopic studies on bioactive polyacetylenes and other plant components in wild carrot root. J. Nat. Prod. 74:1757-1763.

Sampedro, J., and Cosgrove, D. J. 2005. The expansin superfamily. Genome Biol. 6:242.

Santamour, F. S., Jr., and Batzli, J. M. 1990. Root-knot nematodes on willows: Screening of Salix species, cultivars, and hybrids for resistance. J. Arbor. 16:190-196.

Sasanelli, N., and Pierangeli, D. 1994. Response of selected forest trees to Meloidogyne incognita infections. Nematol. Medit. 22:83-85.

Savitzky, A., and Golay, M. J. E. 1964. Smoothing and differentiation of data by simplified least squares procedures. Anal. Chem. 36:1627-1639.

Shi, R., Sun, Y. H., Li, Q., Heber, S., Sederoff, R., and Chiang, V. L. 2010. Towards a systems approach for lignin biosynthesis in Populus 
trichocarpa: Transcript abundance and specificity of the monolignol biosynthetic genes. Plant Cell Physiol. 51:144-163.

Slavov, G., and Zhelev, P. 2010. Salient biological features, systematics, and genetic variation of Populus. Pages 15-38 in: Genetics and genomics of Populus. Springer, New York.

Triantaphyllou, A. C. 1960. Sex determination in Meloidogyne incognita Chitwood 1949 and intersexuality in M. javanica (Treub, 1885) Chitwood, 1949. Ann. Inst. Phytopath. Benaki 3:12-31.

Trudgill, D. L., and Blok, V. C. 2001. Apomictic, polyphagous root-knot nematodes: Exceptionally successful and damaging biotrophic root pathogens. Annu. Rev. Phytopathol. 39:53-77.

Uragami, C., Galzerano, D., Gall, A., Shigematsu, Y., Meisterhans, M., Oka, N., Iha, M., Fujii, R., Robert, B., and Hashimoto, H. 2014. Light-dependent conformational change of neoxanthin in a siphonous green alga, Codium intricatum, revealed by Raman spectroscopy. Photosynth. Res. 121:69-77.

Van Doorsselaere, J., Baucher, M., Chognot, E., Chabbert, B., Tollier, M.-T., Petit-Conil, M., Leplé, J.-C., Pilate, G., Cornu, D., Monties, B., Montagu, M., Inzé, D., Boerjan, W., and Jouanin, L. 1995. A novel lignin in poplar trees with a reduced caffeic acid/5-hydroxyferulic acid $O$-methyltransferase activity. Plant J. 8:855-864.

Vanholme, B., Cesarino, I., Goeminne, G., Kim, H., Marroni, F., Van Acker, R., Vanholme, R., Morreel, K., Ivens, B., Pinosio, S., Morgante, M.,
Ralph, J., Bastien, C., and Boerjan, W. 2013. Breeding with rare defective alleles (BRDA): A natural Populus nigra HCT mutant with modified lignin as a case study. New Phytol. 198:765-776.

Vanholme, R., Morreel, K., Darrah, C., Oyarce, P., Grabber, J. H., Ralph, J., and Boerjan, W. 2012a. Metabolic engineering of novel lignin in biomass crops. New Phytol. 196:978-1000.

Vanholme, R., Storme, V., Vanholme, B., Sundin, L., Christensen, J. H., Goeminne, G., Halpin, C., Rohde, A., Morreel, K., and Boerjan, W. 2012b. A systems biology view of responses to lignin biosynthesis perturbations in Arabidopsis. Plant Cell 24:3506-3529.

Vieira, P., Kyndt, T., Gheysen, G., and de Almeida Engler, J. 2013. An insight into critical endocycle genes for plant-parasitic nematode feeding sites establishment. Plant Signal. Behav. 8:e24223.

Wan, X., Landhäusser, S. M., Lieffers, V. J., and Zwiazek, J. J. 2006. Signals controlling root suckering and adventitious shoot formation in aspen (Populus tremuloides). Tree Physiol. 26:681-687.

Wieczorek, K. 2015. Cell wall alterations in nematode-infected roots. Pages 61-90 in: Advances in Botanical Research, Vol 73. Elsevier Ltd., Amsterdam.

Wuyts, N., Lognay, G., Swennen, R., and De Waele, D. 2006. Nematode infection and reproduction in transgenic and mutant Arabidopsis and tobacco with an altered phenylpropanoid metabolism. J. Exp. Bot. 57: 2825-2835. 